\title{
Analysis of a Fictive Active e-Trailer
}

\author{
Steven Boonstra * (iD) and Frank Rieck \\ Research Centre Sustainable Port Cities, Rotterdam University of Applied Science, Heijplaatstraat 23, \\ 3089 JB Rotterdam, The Netherlands; f.g.rieck@hro.nl \\ * Correspondence: boontje328@live.nl
}

Received: 14 May 2018; Accepted: 30 May 2018; Published: 4 June 2018

\begin{abstract}
Trucks consume an enormous amount of diesel annually and contribute significantly to the total $\mathrm{CO}_{2}$ emissions around the world. Electrification of these freight vehicles would lead to a reduction in fuel consumption and $\mathrm{CO}_{2}$ emissions. Trailers, as part of heavy freight vehicles, are a great opportunity for innovative change. Electrifying the trailer would allow the combustion engine of the truck to cooperate with the electric motors in the trailer. The trailer would be able to regenerate energy using the electric motors built into the rear axis of the trailer. The energy that is regenerated could be stored in a battery power pack for later use. Using the principle of peak shaving, the combustion engine would be assisted by the active e-trailer. Peak shaving would occur when the calculated load on the combustion engine is highly above average, for example, during acceleration, climbing a hill, or during high speed. Energy from the power pack could be routed to the electric motors, adding propulsive force. This analysis of a fictive active e-trailer has focused on reducing fuel consumption and emissions. The energy consumption of the trailer and the energy regeneration were studied. For this analysis, two vehicle configurations were simulated within the MATLAB Simulink: one truck-trailer combination without the e-trailer application and one truck-trailer combination with the e-trailer application. Differences between the two simulated vehicle combinations have been analyzed and documented. The whole system would be self-sustaining by using the regenerating energy from braking and adjusting its assisting function according to the energy level of the power pack. However, better results would be achieved by charging the power pack periodically. By doing so, the reduction of fuel cost and emissions could be significantly improved.
\end{abstract}

Keywords: freight transport and heavy-duty vehicles; special vehicle technologies; (plug-in) hybrid powertrain; environmental impact assessments

\section{Introduction}

Rotterdam is an international port city where many freight vehicles come and go from the port. These vehicles deliver their load and return to their (international) home base. Many people tend to think that freight vehicles primarily used for long distance transport; however, a lot of cargo is also being driven into the city by trucks. These trucks move cargo from distribution centers to Rotterdam and back, and also distribute their load from one region within the port area to another. The trucks consume an enormous amount of diesel and are responsible for a third of the total road transport-related $\mathrm{CO}_{2}$ emission of Rotterdam, which is expected to rise above $45 \%$ by 2025 [1]. The city has been searching for possible solutions to prevent this from happening. On a small scale, the electrification of trucks has started for city distribution in order to reduce $\mathrm{CO}_{2}$ emissions. The port area is a great place to start with electrification since the trucks within the area drive short distances before unloading and heading to the next location. Electric vehicles prove to be much more efficient here.

However, for heavy transport, there are still a large number of international diesel-consuming vehicles on the road. This fleet is far too big to completely convert it to electric vehicles; thus, other options for reducing the massive $\mathrm{CO}_{2}$ emissions have to be explored. Moreover, modern day diesel 
trucks are highly developed, making it even more difficult to reduce emissions. The engines of these trucks have been created in such a way that, regarding the reduction of emissions, it leaves barely any room for improvement. It can be argued that other areas have to be researched in order to reduce emissions.

Currently, one might find the best results within e-technology. Electric components have many applications and they can prove their worth during the inevitable changes within the automotive sector. Preparing for change right now is the best thing to do in order to prevent major problems from happening in the future. Completely converting to electric trucks is not feasible yet but working towards it is.

Most heavy freight trucks are trucks with an attached trailer on which the load is transported. The truck usually provides the propulsive force for the complete vehicle combination. When comparing combustion engines to electric motors one can derive positive and negative aspects from both techniques. Combustion engines are currently dominating the world of cargo transport over land and merely a small percentage of cargo transport is done by electric vehicles. However, before the combustion engines can effectively be replaced by electric motors, a great number of problems must be dealt with during the transition phase. A way to solve this, might be combining the best of both? This question was the main drive behind the creation of the e-trailer concept. The e-trailer is a combination of a truck and a modified trailer. As an example, for this study a trailer is equipped with two direct drive in-wheel electric motors and a power pack of limited size, customized to its expected application.

The extra electric propulsion from the trailer would open new beneficial possibilities: regenerative braking, lower fuel consumption, increased efficiency of the diesel engine, and more. The concept differs greatly from other existing electric trailers since it utilizes power packs rather than capacitors to store the electric energy and the stored energy could be used for propulsion. The concept will be described further in the next chapter, along with its functions and components. Chapter three is dedicated to the various configurations that would be possible with the e-trailer.

\section{Call for Alternative Technology: Active e-Trailer}

With the described adjustments regarding the e-trailer concept in the introduction chapter, the modified trailer covers a new set of added functions. These functions are listed below and explained further in this chapter.

1. The e-trailer provides extra propulsive force when needed

2. Direct drive motors lead to high efficiency and minimal energy loss

3. The power pack can be charged by regenerative braking and a plug-in cable (option)

4. The e-trailer can function as a hybrid or full electric, cutting its emissions greatly

5. Using energy for the electric motors increases the active radius of the truck

6. Regenerative braking is enabled, resulting in lower fuel consumption and energy recycling

7. Installment of a communication unit would allow the system to work with any regular truck

\section{Functions and Components Explained}

(1) Adding an e-trailer to a regular truck requires an additional communication unit between the truck and the trailer. Sensors would detect the moments in which the freight vehicle could use assistance the most. The trailer would then act upon the readings of the sensors and add propulsive force in order to assist the truck when instructed to do so. There are many variables [2] to be taken into account in order for this to be possible, such as jackknifing, the speed of the vehicle combination, the efficiency of the combustion engine and the electric motor under variable circumstances, the power output of both power sources, the state of charge of the power pack, and many more. Remarkably, they all come together in an engineered strategy that allows the system to determine when it is safe, efficient, and required to add power through the e-trailer. 
(2) There are many electric motors that can be used to electrify a trailer. When it comes to energy efficiency, direct drive motors are ahead of similar technologies within the automotive sector. With efficiency up to $92 \%[3,4]$, this technology reduces energy loss tremendously and would improve the performance of the e-trailer. Direct drive motors consist of very few parts and do not need any gearbox, differential or other form of transmission to transmit power. Additional parts usually waste some of the energy in order to work; therefore, it is of high importance to use as few parts and transmissions as possible. This is where the strength of the direct drive motors lies and it also explains why its efficiency can reach $92 \%$. Preservation of energy will become very important in the next generations to come. Waste is not going to be tolerable anymore if we want to push technology further. The direct drive technology is taking a big leap in the right direction.

(3) Battery power packs are present day's best solution for an energy carrier within the automotive sector and can be used for this concept. The direct drive motors can be installed on a single axle of the trailer and would be able to perform regenerative braking. Regenerative braking occurs when the wheels are actively slowing down the vehicle when no increase of speed is desired, the driver is lifting the throttle pedal or using the braking paddle. When the motors are engaged, they serve as a generator and produce energy rather than consume it. However, this would slow the vehicle; therefore, it has to be done strategically in order to optimize the function and prevent it from wasting precious propulsive energy. When energy is produced by the generative function of the electric motors, it could be channeled to the power pack and stored for future use.

(4) The e-trailer could fulfill various functions. Firstly, it would become part of a hybrid powertrain, which would consume both diesel and electricity. The electricity would come mainly from regenerative braking and would be first stored in the power pack. The power pack can be charged prior to shipping cargo. This way, there would be a supply of energy available for use without having to drive first and gather energy from braking. If the power pack were not charged at the start of a (long) drive, regenerative braking would allow the power pack to charge and discharge when required. This means that the truck-trailer combination would be assisted by energy that is generated solely by regenerative braking (unless the power pack is charged at some point via an external source).

A hybrid combination of a combustion engine and an e-trailer would need a preset distribution of power and can be further improved by implementing the principle of peak shaving. Peak shaving focusses on the heavy-duty moments of the combustion engine and removes the peaks by requesting power from the electric motors. This way, the combustion engine would have fewer inefficient heavy-duty moments and would have a better overall performance. In addition, electric motors are highly capable of delivering the requested power while maintaining a high efficiency level. The overall efficiency increases and, therefore, a lot of energy and diesel would be spared compared to the energy efficiency of regular trucks.

Secondly, the e-trailer could fully power the vehicle combination with electricity for a certain duration, resulting in zero-emission output. Within the city of Rotterdam, this function would be extremely handy since the city has a zero-emission policy. Regular trucks will not be allowed within the city due to their high emission output. A fully electric vehicle would be granted access to the city.

Lastly, the e-trailer could be set in such a way that it would generate energy solely by regenerative braking, without using energy for the electric motors. This would enable the power pack to regulate its state of charge and preserve energy for later which would, in turn, enhance its lifetime.

Clients will be asked to share information about their load case of the truck and daily routines. With this information, the e-trailer could be altered to perform its best within that particular case. This would allow its use to be maximized.

(5) The active radius is increased. The reason for this is that the peak shaving principle is applied to the vehicle combination, even when no hybrid configuration is selected. The trailer will automatically select moments when the truck is having a rough time, providing enough 
propulsion and assistance for the vehicle combination. In turn, this will lower the power demand of the combustion engine. Since the combustion engine consumes diesel and has a separate tank for this, the active radius can be calculated based on the amount of fuel the tank is able to hold. When adding the e-trailer, the capacity of the power pack will be added to the total energy supply, thus increasing the active radius of the vehicle combination.

(6) Regenerative braking has many advantages. Since it automatically slows the vehicle due to the inertia of the generators, the vehicle has to brake less with its mechanical braking system. This would save a great deal of wear on the braking system of the truck, thus increasing the braking system's overall lifetime.

Furthermore, regenerative braking generates energy that could be channeled back to the power pack. This energy could then be used to power the electric motors. When the electric motors provide power, the power would be deducted from the overall demand of power by the vehicle combination, resulting in a lower amount of power provided by the combustion engine. A lower amount of power means a lower amount of fuel consumption. Therefore, regenerative braking would indirectly cause the fuel consumption to drop. Also, since the electric motors are more efficient than the combustion engines, the overall efficiency of energy usage would increase greatly.

(7) Building e-trailers will prove to be quite simple. First, the electric motors have to be equipped on an axle of a standard trailer. Then, the size of the power pack has to be determined. It will be based on the application where the trailer is going to provide its services. Next, the power pack needs to be installed in the trailer; in most cases this will not affect the cargo hold of the trailer. However, concessions for weight reduction might be in order when it comes to the total mass of the vehicle combination. Finally, a communication unit would have to be installed to connect the trailer with the truck. This last component is very important because it guarantees safety and affects the efficiency of the e-trailer.

\section{Research: Analyzing Possible Configurations}

The research has been conducted mainly within a virtual simulation environment (MATLAB Simulink). By thoroughly analyzing the concept and exploring the possibilities and limitations within the physical world, a set of simulations was created from which fuel consumption and emission reduction could be derived. The focus of this research was the system behind the implementation of the trailer. How is it going to work? What affects the fuel consumption and how will this concept increase energy efficiency? What variations of the e-trailer are there?

While analyzing the e-trailer, the power ratio between the truck and the e-trailer has been altered. Since the e-trailer is still in the concept phase, a stable power ratio between truck and e-trailer has yet to be discovered before further optimization of the concept. For the simulation of this concept, it was important to include the specifications of the truck engine (MAN LOH31, $353 \mathrm{~kW}$ ) [5] and electric motors (e-Traction, TheWheel SM500/3, part of TheMotion) [2] used. For power storage, the Valence U27-12XP cells were used. Different trucks will not affect the results as much. However, using different electric motors will since the direct drive motors have higher efficiency than common electric motors.

\subsection{Driving Cycle}

The driving cycle, shown in Figure 1, affects the outcome of the simulation. On the one hand, there are trucks that need to drive long distances due to certain jobs. Each will have to perform its best while driving at various high speeds. On the other hand, there are trucks that need to drive within urban areas. These trucks will have to brake a lot, accelerate swiftly, perform well while driving at speeds ranging from $0-35 \mathrm{~km} / \mathrm{h}$, and produce less emissions than the trucks on the highway. All these variables were taken into account and, as a result, several profiles have been created for each application region of a truck. Aside from the written profiles, a driving cycle has been plotted and simulated. The simulation can use this as input to simulate vehicle speed over time. There are three 
main application categories in which any truck can be placed: urban, suburban, and highway. Urban traffic usually ranges between 0 and $30 \mathrm{~km} / \mathrm{h}$ while performing many acceleration and deceleration actions. Suburban traffic ranges between 0 and $50 \mathrm{~km} / \mathrm{h}$ with fewer changes in speed compared to the urban category. Highway traffic ranges between 0 and $80 \mathrm{~km} / \mathrm{h}$ with slight changes in speed. The highway category vehicles drive at a high speed continuously for long periods of time. Since the case study involved the port city of Rotterdam, a range between 0 and $60 \mathrm{~km} / \mathrm{h}$ was converted into a driving cycle. This allowed for a realistic view of the main two categories (urban and suburban) and an idea of higher speed performance. For this, the Hyzem urban driving cycle was used. For longer simulations, this cycle was repeated until the total distance travelled was sufficient.

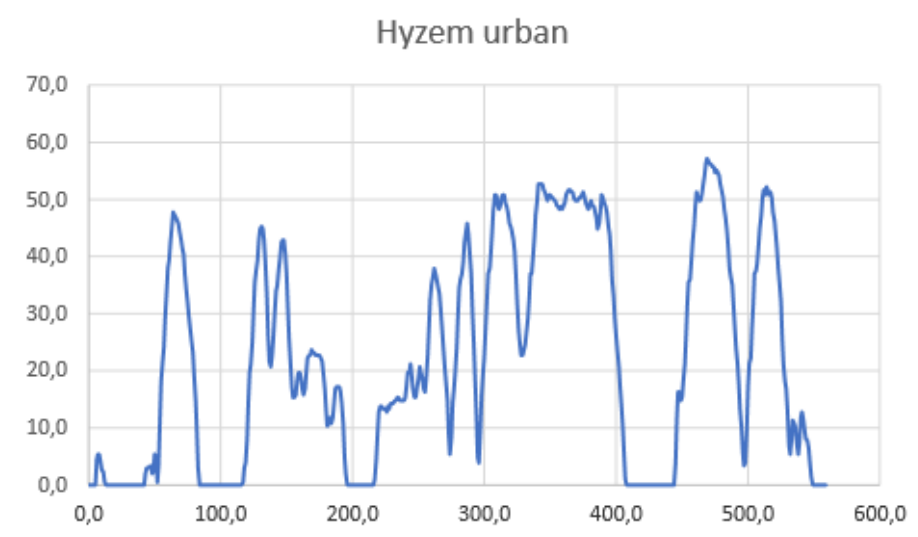

Figure 1. The Hyzem urban driving cycle.

\subsection{Power Ratios}

For every application, an ideal power ratio between the combustion engine and the electric motors could be found. Electric motors perform well under low rpm (revolutions per minute of the wheel) but start losing some efficiency when the rpm becomes too high, while the combustion engine of the truck has a gearbox and is engineered to perform well during high speed. By combining the strengths and weaknesses of both engine and motors, a strategy of power ratios between the combustion engine and electric motors was developed. The e-trailer provides more power when it is most efficient and less power under high speeds, with the exception of the truck requesting additional power through the peak shaving assist. The exact power ratios used within the research cannot be disclosed.

\subsection{Fuel Economy}

By using the driving cycle and determining a strategy for different power ratios, which are guided by power demand and vehicle speed, accurate assumptions have been made regarding the fuel economy. The energy efficiency increased as a result of the power ratio strategy. This will result in a reduction in both fuel consumption and emissions. The power demand of the combustion engine is directly linked to the amount of emissions and fuel consumption. Where a higher demand will result in more fuel consumption and more emissions, a lower demand will result in less fuel consumption and less emissions. Additionally, a higher efficiency of the combustion engine will cut both fuel consumption and emission output. This is exactly what the power ratio strategy aims for: finding a balance between ideal efficiency regions of both the combustion engine and the electric motors and reducing the power demand by the combustion engine as much as possible. However, sufficient energy has to be available in order to execute this strategy.

\section{Results}

Table 1 [6] shows the results of the e-trailer in comparison to a regular trailer based on the Hyzem urban cycle (the cycle was repeated 15 times). Unfortunately, it is not yet clear how much it would cost 
to convert a regular trailer into an e-trailer. Consequently, a complete analysis of the financial aspect of the e-trailer was not possible. However, the total diesel savings could be derived, thus giving one an idea of the effectiveness of the e-trailer.

Table 1. Comparison between the e-trailer and regular trailer.

\begin{tabular}{lc}
\hline e-Trailer Table (Daily Charging) & Results \\
\hline Converting to e-trailer cost $(€)$ & $\mathrm{N} / \mathrm{A}$ \\
Used energy per cycle & $41.48 \mathrm{kWh}$ \\
Regenerated energy per cycle & $17.26 \mathrm{kWh}$ \\
Total energy usage & $24.2 \mathrm{kWh}$ \\
Total used diesel per cycle, regular trailer $(\mathrm{L})$ & 13.70 \\
Total used diesel per cycle, e-trailer $(\mathrm{L})$ & 5.61 \\
Cost kWh green energy $(€)$ & 0.19 \\
Cost kwh fast charge energy $(€)$ (option) & 0.36 \\
Fuel reduction each cycle $(\%)$ & 59.03 \\
COST Liter diesel $(€)$ & 1.35 \\
Emission rights per year $\left(6 € / 1000 \mathrm{~kg} \mathrm{CO}_{2}\right)$ & $47.04 €$ \\
Annual fuel reduction $(€)$ & 3.986 \\
Cost of green energy $(€)$ & 1.678 \\
Cost of fast charge energy $(€)(\mathrm{OTION})$ & 3.180 \\
Total diesel savings compared to a regular trailer $(\%)$ & 59 \\
\hline
\end{tabular}

The fuel savings would be remarkable. A reduction of 59\% would have a great impact on present day's demand for diesel. It would also allow for $\mathrm{CO}_{2}$ emissions per kilometer to drop substantially. The high number is the result of applying the power ratio strategy. As mentioned in Section 3.2, finding a balance between ideal efficiency regions and peak shaving increases the overall efficiency and reduces the fuel consumption. Developing the power ratio strategy more might lead to a further reduction. Even so, this would require further research and since there is no physical e-trailer yet, it is very hard to verify whether further improvements would have the same results in reality.

\section{Discussion}

The current technologies regarding combustion engines are reaching their limit and, thus, new ideas and improvements are sought after. A lot of research regarding this subject has been done and further research would instantly mean improving the current strategy. However, building a prototype and validating the current research would be a great first step forward.

It is not strange to seek a temporary solution within a hybrid system. The combustion engine has its strengths but also its weaknesses. The same can be said for electric motors. Combining the best of both is likely to be the appropriate response to our increasing demand for emission reduction. Also, the current combustion engines can be downsized as a result of the assisting properties of the e-trailer, which allows for even more reduction in fuel consumption and emissions. The introduction of the e-trailer creates new gateways for a solution to the climate problems that the world is facing today.

Author Contributions: Conceptualization, S.B. and F.R.; Methodology, S.B. and F.R.; Software, S.B.; Validation, S.B. and F.R.; Formal Analysis, S.B. and F.R.; Investigation, S.B.; Writing-Original Draft, S.B.; Preparation, S.B. and F.R.; Writing-Review \& Editing, S.B. and F.R.; Visualization, S.B.; Supervision, F.R.; Project Administration, S.B.; Funding Acquisition, F.R.

Acknowledgments: We would like to thank Roelof de Haan of Carrosserie.nl for his guidance and contribution to this project. Hehas been a solid rock throughout this research. Every meeting was of great use and resulted in a lot of progress during the subsequent moments. Gudo Ebbers, former worker at e-Traction, also contributed greatly throughout the research. He gave a lot of advice and insights which were very helpful. The results would not be of the same quality without their input and for that we are thankful.

Conflicts of Interest: The authors declare no conflicts of interest. 


\section{References}

1. Inventarisatie en Vergelijking Jaaremissies 2007-2015; DCMR Milieudienst Rijnmond: Rotterdam, The Netherlands, 2016.

2. Hogt, R.M.M. Aandrijftechnieken; Hogeschool Rotterdam: Rotterdam, The Netherlands, 2014.

3. e-Traction. Product Sheet the Wheel; e-Traction: Apeldoorn, The Netherlands, 2015.

4. Ziehl-Abegg. Extern ZAwheel Efficiency; Ziehl-Abegg: Kuenzelsau, Germany, 2013.

5. MAN. Product Range Brochure MAN Engines for Buses and Special-Purpose Vehicles; MAN: München, Germany, 2016.

6. Boonstra, S.R.R. Energieanalyse Naar Fictieve Actieve E-Trailer; Hogeschool Rotterdam: Rotterdam, The Netherlands, 2017.

(c) (1)

(C) 2018 by the authors. Licensee MDPI, Basel, Switzerland. This article is an open access article distributed under the terms and conditions of the Creative Commons Attribution (CC BY) license (http://creativecommons.org/licenses/by/4.0/). 